\title{
Noninvasive ventilation as first-line treatment for acute respiratory distress syndrome: The time is not ripe yet!
}

\author{
Alladi Mohan, J. Harikrishna
}

Noninvasive ventilation (NIV) is a method of delivering mechanical ventilatory support via an upper airway mask without the need for tracheal intubation. Early reports of the applications of NIV in the treatment of acute respiratory failure date back to the mid-1940s when Motley et al. ${ }^{[1]}$ used intermittent positive inspiratory pressure ventilation (IPPV) via an anesthesia mask in the treatment of acute respiratory failure caused by pneumonia, pulmonary edema, near-drowning, Guillain-Barré syndrome, and acute severe asthma. ${ }^{[1]}$ However, with the emergence of invasive mechanical ventilation, the use of NIV took a back seat. The clinical application of NIV re-emerged in the 1980s when it was successfully used to treat obstructive sleep apnea, ${ }^{[2]}$ and respiratory failure in patients with neuromuscular diseases. ${ }^{[3]}$ Thereafter, the last two decades have witnessed a phenomenal increase in the clinical applications of NIV in the acute care setting. ${ }^{[4]}$ NIV has emerged as a modality of choice in the management of severe acute exacerbation of chronic obstructive pulmonary disease (COPD) and cardiogenic pulmonary edema (Grade 1 [strong] recommendation).$^{[5]}$ Evidence is accumulating for use of NIV in patients with acute respiratory failure in the following settings: Immunosuppressed patients, following abdominal surgery and lung resection, for facilitating early extubation in patients with COPD, and as a transition to spontaneous breathing after planned extubation in patients at high risk for recurrent respiratory failure, such as, age $>65$ years, cardiac failure as the cause of intubation, Acute Physiology and Chronic Health

\section{From:}

Department of Medicine, Division of Pulmonary, Critical Care and Sleep

Medicine, Sri Venkateswara Institute of Medical Sciences, Tirupati,

Andhra Pradesh, India

\section{Correspondence:}

Dr. Alladi Mohan, Department of Medicine, Division of Pulmonary, Critical Care and Sleep Medicine, Sri Venkateswara Institute of Medical Sciences,

Tirupati - 517 507, Andhra Pradesh, India.

E-mail: alladimohan@svims.gov.in

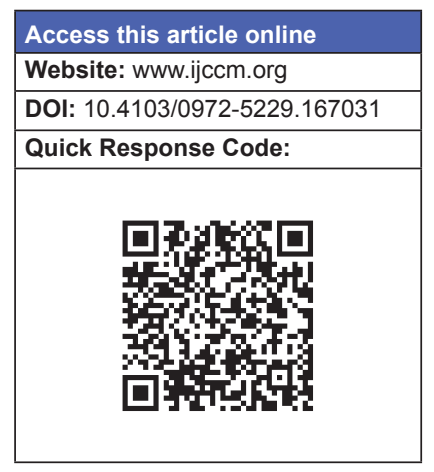

Evaluation (APACHE) II score greater than 12 at the time of extubation (grade 2 [weak] recommendation). ${ }^{[5]}$ NIV has many advantages compared to IPPV. It is easy to administer, avoids the need to secure an invasive airway, is associated with fewer complications, and a shorter hospital stay. Further, the cost of treatment and burden on health care system is also less with NIV. ${ }^{[5]}$

Acute respiratory distress syndrome (ARDS), characterized by acute onset bilateral pulmonary infiltrates and refractory hypoxemia is associated with a high mortality. The standard care for patients with ARDS includes early IPPV with low tidal volume, high positive end-expiratory pressure, among others. The benefits and harms of NIV in ARDS have not been systematically evaluated. For conditions resulting in acute hypoxemic respiratory failure such as acute exacerbation of bronchial asthma, ARDS, severe community-acquired pneumonia (CAP), and chest trauma, NIV is not considered to be the modality of choice. ${ }^{[5,6]}$ However,

This is an open access article distributed under the terms of the Creative Commons Attribution-NonCommercial-ShareAlike 3.0 License, which allows others to remix, tweak, and build upon the work non-commercially, as long as the author is credited and the new creations are licensed under the identical terms.

How to cite this article: Mohan A, Harikrishna J. Noninvasive ventilation as first-line treatment for acute respiratory distress syndrome: The time is not ripe yet!. Indian J Crit Care Med 2015;19:571-3. 
in these conditions, including ARDS, NIV has been tried when there were no contraindications. Evidence regarding the use of NIV in acute respiratory failure excluding COPD and cardiogenic pulmonary edema is limited to case series, observational studies and few randomized controlled trials (RCT) that included a heterogeneous, mixed population of patients with various etiological causes which had revealed conflicting results. One $\mathrm{RCT}^{[7]}$ suggested that in patients with acute hypoxemic respiratory failure which included patients with ARDS, addition of NIV to standard medical management resulted in decreased rate of endotracheal intubation, length of Intensive Care Unit (ICU) stay, and mortality in a subset of patients with arterial partial pressure of carbon dioxide more than $45 \mathrm{~mm}$ of $\mathrm{Hg}$ compared to patients who received standard medical care and oxygen inhalation. Two other RCTs ${ }^{[8,9]}$ also showed beneficial effects of addition of NIV to standard medical therapy compared to oxygen inhalation. Another $\mathrm{RCT}^{[10]}$ showed NIV neither reduced need for intubation nor improved the clinical outcome. Further, an RCT ${ }^{[1]}$ that compared NIV with IPPV concluded that NIV is as effective as IPPV in improving gas exchange and associated with fewer complications in ICU setting. A systematic review ${ }^{[12]}$ that compared standard therapy alone with NIV along with standard therapy in patients with acute hypoxemic respiratory failure showed that NIV decreased the rate of endotracheal intubation, length of ICU stay and ICU mortality. In all these studies, the proportion of ARDS patients has been very small and significant heterogeneity observed in the results limits their extrapolation to patients with ARDS.

In patients with moderate to severe ARDS, evidence comparing the use of NIV with IPPV head-on is sparse and is limited to few observational studies and no RCTs. In one observational study ${ }^{[13]}$ in patients with acute lung injury (ALI) / ARDS who received a trial with NIV, tracheal intubation could be avoided in $40 \%$ of patients; however, a significantly higher mortality was observed in patients who had received NIV trial compared with patients who were intubated early. In patients with ARDS, while on one hand a substantial reduction in the need for tracheal intubation has been observed with the use of NIV, a substantial increase in mortality has been a cause for concern. ${ }^{[13]} \mathrm{A}$ meta-analysis ${ }^{[14]}$ that evaluated on the role of NIV in ARDS showed no significant benefit of the addition of NIV to standard medical therapy. In another meta-analysis, ${ }^{[15]}$ it was observed that NIV avoided intubation in 50\% of patients; however, the authors concluded that in view of significant heterogeneity these results should be interpreted with caution. Further, a more recent meta-analysis ${ }^{[16]}$ had also shown that, in patients with ALI/ARDS, while early use of NIV can decrease the endotracheal intubation rate, it did not change the mortality of these patients. Further, evidence is also available that failed NIV is associated with intubation-related complications and increased risk of death. ${ }^{[17]}$

In this issue of the IJCCM, Sehgal et al. ${ }^{[18]}$ reported their experience with NIV in patients with ARDS. In this prospective observational study ${ }^{[18]}$ conducted in patients with mild to moderate ARDS, the authors reported that NIV has avoided intubation in $44 \%$ of subjects and univariate analysis has shown that baseline APACHE II score $>17$ and lack of improvement in the ratio of arterial oxygen tension $\left(\mathrm{PaO}_{2}\right)$ to fraction of inspired oxygen $\left(\mathrm{FIO}_{2}\right)>150$ after $1 \mathrm{~h}$ of initiation predicted NIV failure. Further, significantly higher mortality in patients with NIV failure compared with no mortality observed in those with NIV success (19/23 vs. 0/18) is another cause for concern. Patients with NIV failure had more severe disease characterized by a higher median (interquartile range [IQR]) base line APACHE II score and $\mathrm{PaO}_{2} / \mathrm{FIO}_{2}$ ratio. The authors report that the median (IQR) time to intubation was $3(1-4) \mathrm{h}$. This delay in initiating tracheal intubation and mechanical ventilation in patients with more severe disease could also have contributed to the higher mortality observed in the present study.

While the observations from the present study ${ }^{[18]}$ raise hope in terms of avoiding tracheal intubation, the results this study ${ }^{[15]}$ should be interpreted with caution. This present study ${ }^{[15]}$ where the authors have chosen a "sample of convenience" is underpowered as the sample studied $(n=41)$ is very small. As of now, NIV should be used with caution in patients with ARDS. Use of NIV is patients with ARDS should be considered only in ICUs equipped with facilities for round-the-clock monitoring and carrying out tracheal intubation as soon as it is required. Patients in whom NIV is being considered should be judiciously selected and carefully monitored for NIV failure with an intention to intubate as early as possible in case of NIV failure. At present, sufficient evidence is inadequate to make a strong recommendation to support the routine use on NIV as an initial mode of choice in patients with ARDS. Prospective, randomized, multicentric RCTs with an appropriate sample size are required to generate evidence regarding the role of NIV in patients with ARDS.

\section{References}

1. Motley HL, Werko L, Cournand A, Richards DW. Observations on the clinical use of intermittent positive pressure. J Aviat Med 1947;18:417-35.

2. Sullivan CE, Issa FG, Berthon-Jones M, Eves L. Reversal of obstructive 
sleep apnoea by continuous positive airway pressure applied through the nares. Lancet 1981;1:862-5.

3. Ellis ER, Bye PT, Bruderer JW, Sullivan CE. Treatment of respiratory failure during sleep in patients with neuromuscular disease. Positive-pressure ventilation through a nose mask. Am Rev Respir Dis 1987;135:148-52.

4. Schnell D, Timsit JF, Darmon M, Vesin A, Goldgran-Toledano D, Dumenil AS, et al. Noninvasive mechanical ventilation in acute respiratory failure: Trends in use and outcomes. Intensive Care Med 2014;40:582-91

5. Keenan SP, Sinuff T, Burns KE, Muscedere J, Kutsogiannis J, Mehta S, et al. Clinical practice guidelines for the use of noninvasive positive-pressure ventilation and noninvasive continuous positive airway pressure in the acute care setting. CMA.J 2011;183:E195-214.

6. Chawla R, Khilnani GC, Suri JC, Ramakrishnan N, Mani RK, Prayag $\mathrm{S}$, et al. Guidelines for noninvasive ventilation in acute respiratory failure. Indian J Crit Care Med 2006;10:117-47.

7. Wysocki M, Tric L, Wolff MA, Millet H, Herman B. Noninvasive pressure support ventilation in patients with acute respiratory failure. A randomized comparison with conventional therapy. Chest 1995;107:761-8.

8. Antonelli M, Conti G, Bufi M, Costa MG, Lappa A, Roceo M, et al. Noninvasive ventilation for treatment of acute respiratory failure in patients undergoing solid organ transplantation: A randomized trial. JAMA 2000;283:235-41.

9. Ferrer M, Esquinas A, Leon M, Gonzalez G, Alarcon A, Torres A. Noninvasive ventilation in severe hypoxemic respiratory failure: A randomized clinical trial. Am J Respir Crit Care Med 2003;168:1438-44.

10. Delclaux C, LHer E, Alberti C, Mancebo J, Abroug F, Conti G, et al. Treatment of acute hypoxemic nonhypercapnic respiratory insufficiency with continuous positive airway pressure delivered by a face mask: A randomized controlled trial. JAMA 2000;284:2352-60.

11. Antonelli M, Conti G, Roceo M, Bufi M, De Blasi RA, Vivino $\mathrm{G}$, et al. A comparison of noninvasive positive-pressure ventilation and conventional mechanical ventilation in patients with acute respiratory failure. N Engl J Med 1998;339:429-35.

12. Keenan SP, Sinuff T, Cook DJ, Hill NS. Does noninvasive positive pressure ventilation improve outcome in acute hypoxemic respiratory failure? A systematic review. Crit Care Med 2004;32:2516-23.

13. Antonelli M, Conti G, Esquinas A, Montini L, Magoiore SM, Bello G, et al. A multiple-center survey on the use in clinical practice of noninvasive ventilation as a first-line intervention for acute respiratory distress syndrome. Crit Care Med 2007;35:18-25.

14. Agarwal R, Reddy C, Aggarwal AN, Gupta D. Is there a role for noninvasive ventilation in acute respiratory distress syndrome? A meta-analysis. Respir Med 2006;100:2235-8.

15. Agarwal R, Aggarwal AN, Gupta D. Role of noninvasive ventilation in acute lung injury/acute respiratory distress syndrome: A proportion meta-analysis. Respir Care 2010;55:1653-60.

16. Luo J, Wang MY, Zhu H, Liang BM, Liu D, Peng XY, et al. Can non-invasive positive pressure ventilation prevent endotracheal intubation in acute lung injury/acute respiratory distress syndrome? A meta-analysis. Respirology 2014;19:1149-57.

17. Mosier JM, Sakles JC, Whitmore SP, Hypes CD, Hallett DK, Hawbaker KE, et al. Failed noninvasive positive-pressure ventilation is associated with an increased risk of intubation-related complications. Ann Intensive Care 2015;5:4.

18. Sehgal IS, Chaudhuri S, Dhooria S, Agarwal R, Chaudhry D. A study on the role of noninvasive ventilation in mild-to-moderate acute respiratory distress syndrome. Indian J of Crit Care Med 2015;19:593-99. 